\title{
Epistemología de la literatura y educación literaria en el contexto escolar colombiano*
}

\author{
Epistemology \\ of Literature and \\ Literary Education \\ in the Colombian \\ School Context
}

\author{
Epistemologia \\ da literatura e da \\ educação literária \\ no contexto escolar \\ colombiano
}

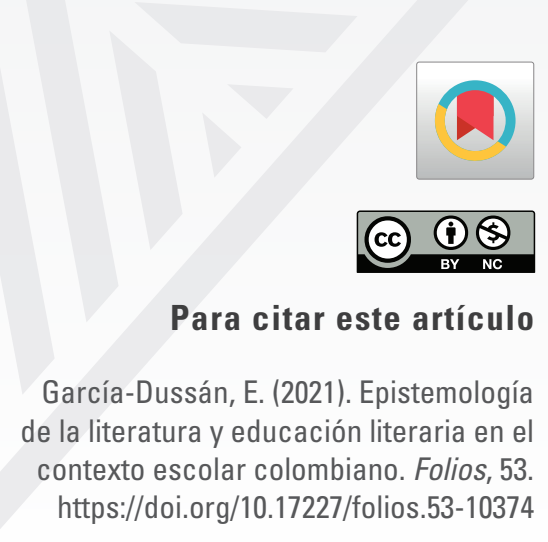

García-Dussán, E. (2021). Epistemología de la literatura y educación literaria en el htps:/doi.

Artículo recibido $01 \cdot 08 \cdot 2019$

Artículo aprobado $08 \cdot 06 \cdot 2020$

Doctor en Modelos de Enseñanza-Aprendizaje. Profesor de la Universidad Distrital, Francisco José de Caldas.

Correo electrónico: eagarciad@udistrital.edu.co 


\title{
Resumen
}

En este artículo de reflexión, nos proponemos esbozar los elementos fundamentales de una epistemología de la literatura que permita anudar tanto una postura conceptual como una metodológica, a propósito de la educación literaria en la universidad colombiana. Para lograr esto, acudimos a una definición esencialista débil de la literatura y a un método que combina premisas del análisis discursivo y la semiótica literaria, lo que permite construir un conjunto de criterios para la lectura de obras y la creación de textos estéticos como procesos esenciales en el contexto de una educación literaria. El resultado de tal propuesta permite exponer y describir unas alternativas pedagógicas mínimas, cuyo asiento es el concepto de competencia literaria que concede al educando capacidad de fruición, de reflexión crítica, de trabajo inferencial y de creatividad.

\section{Palabras clave}

epistemología de la literatura; literariedad; análisis del discurso; semiótica; educación literaria; competencia literaria

\begin{abstract}
In this reflective paper, we propose to outline the fundamental elements of an epistemology of literature that allows to knot both a conceptual and a methodological posture, regarding literary education in the Colombian university. To achieve this, we turn to a weak essential definition of literature and a method that combines premises of discourse analysis and literary semiotics. This allows us to construct criteria for reading works and creating aesthetic texts as essential processes in the context of literary education. The result of this proposal makes it possible to expose and describe minimum pedagogical keys, whose place is the concept of literary competence that grants to the educator the capacity of fruition, critical reflection,

Keywords

epistemology of literature; literary; discourse analysis; semiotics; literary education; literary competence

Neste artigo de reflexão, propomos delinear os elementos fundamentais de uma epistemologia da literatura que permita vincular uma posição conceitual e também metodológica, no que se refere à educação literária na universidade colombiana. Para tanto, recorremos a uma definição essencialista fraca de literatura e a um método que combina premissas de análise discursiva e da semiótica literária, que nos permite construir um conjunto de critérios para a leitura de obras e a criação de textos estéticos como processos essenciais no contexto de uma educação literária. 0 resultado de tal proposta permite expor e descrever algumas alternativas pedagógicas mínimas, cuja base é o conceito de competência literária que confere ao aluno capacidade de fruição, reflexão crítica, trabalho inferencial e criatividade.
\end{abstract}

Abstract inferential work, and creativity.

\section{Resumo}

\section{Palavras chave}

epistemologia da literatura; literariedade; análise de discurso; semiótica; educação literária; competição literária 


\section{Introducción}

La educación literaria ha estado presente en Occidente desde la Edad Media hasta nuestros días, pero su persistencia en el ambiente letrado nunca ha sido fácil de comprender, ni mucho menos cómodo para llevarse a cabo en la praxis educativa. Así, por caso, ha sido un medio para fortalecer la ortología, para la construcción de conciencia nacional, para la formación de lectores competentes, pretexto para adelantar análisis científicos y comentarios; o bien, para la construcción de hábitos, para despertar el placer de la lectura o para crear textos que reflejen la libre expresión de ideas, entre otras (Lomas, 1999). Todos estos usos de la literatura en la escuela por más de quince siglos, que oscilan entre su concepción como medio o como fin, nos permiten entrever la dificultad para encontrar lugares comunes que sirvan como pretextos para cuestionar la utilidad de ella como espacio académico en la universidad, ' la naturaleza de su objeto de estudio y, sobre todo, el constante interrogante sobre cómo enseñarla. Por ello, muchas veces queda reducida a taxonomías periodizantes y lecturas descontextualizadas, lejanas de funciones formativas, fruitivas y transformativas (Ministerio de Educación Nacional, 2008) e, incluso, deja de lado la falta de estrategias para reconocer el uso estético de la lengua, sin contar con las confusiones para generar criterios de evaluación sobre las actividades llevadas a cabo con obras literarias, bien sea en su lectura o en su producción.

Todo este panorama nos exige buscar posibles explicaciones a propósito de esta falta de coincidencias frente a la forma de entender, practicar y concebir la literatura en el mundo educativo universitario. Así pues, frente a todas estos desconciertos e incógnitas sobre lo que es y lo que debería ser la educación literaria, creemos que un primer paso para comenzar a limitar el camino y a despejar

1 Proponemos situar la reflexión y la propuesta en el nivel universitario, debido a que es allí donde el autor del artículo ha desarrollado seminarios de Pedagogía de la Literatura, a nivel de pregrado y posgrado, orientándolo de esta manera bajo el auspicio de un desarrollo de pensamiento crítico más maduro, apoyado en parte por reflexiones de tipo ético-político y estético, y amparados en el imperio de un interés mucho más claro en relación con las ofertas de los currículos y su relación con intereses investigativos de los educandos. reflexiones sobre su entendimiento y su acción es esbozar, de una manera palmaria y transparente, los fundamentos de una epistemología de la literatura. Lo que se traduce en apoyo para proyectar unos lineamientos pedagógicos que puedan ser desarrollados en la praxis escolar local donde, suponemos, los auditorios han madurado estrategias y habilidades en las modalidades oral y escrita de la lengua materna (v. gr. Reconocimiento de tipologías textuales y sus cualidades, mayor control y auto-regulación de los momentos de la comprensión y la producción textuales, etc.), premisas que pueden ser útiles para fortalecer otro tipo de competencias.

Ahora bien, si aceptamos que este puede ser un nuevo inicio para una re-comprensión de cómo pensar de la educación literaria, definimos la epistemología de la literatura como el conjunto de reflexiones sobre las condiciones que admiten un saber sistemático sobre la literatura, y cuyos productos se pueden abreviar en determinaciones conceptuales y métodos de investigación los cuales, una vez claros, ayuden a generar unos principios generales y unos propósitos de tipo pedagógico (Bobes, 2008; 2012). La ganancia de este esfuerzo es inmediata, la cual podemos enunciar con Fenstermacher (1986), como una "buena enseñanza"; o al menos una mejor, la cual es "buena" en la medida en que el docente que la orquesta puede justificar su praxis en términos epistemológicos.

Explicitada, entonces, la problemática, lanzada una posible solución y entendida conceptualmente su salida, esbozaremos en lo que sigue lo justo para desarrollar esa epistemología, la cual detallaremos hasta sentar un compendio pedagógico que permita regir la praxis literaria en la escuela situada en nuestras condiciones socio-políticas recientes, anhelantes de la construcción de una identidad y una cultura de paz.

\section{Bases para la construcción de una Epistemología de la literatura}

Si nos alejamos de cierto relativismo y escepticismo, podemos afirmar que la realidad existe, que puede ser percibida y que el sujeto es capaz de conocerla 
por medio de un juego lingüístico definido, siempre y cuando esté ajustado a normas de coherencia (semántica y pragmática) o a sus alteraciones puesto que, al revisar la manera como un producto modaliza la lengua, se reconoce su estabilidad previa lo cual, de hecho, es una cualidad frecuente cuando se aborda la obra literaria como manifestación directa de la literatura. Ahora, sobre esta apuesta advertimos algunas problemáticas que se presentan en cada polo del trabajo de la acción literaria; es decir, tanto en su comprensión como en la producción; así, por caso, resaltamos las siguientes:

- Toda obra literaria aparece ante el receptor como un acto lector pues, como afirma Larrosa (2003): “[...] en la lectura lo importante no es el texto sino la relación con el texto” (p. 30). Sin embargo, no todos los sujetos se acercan con iguales estratagemas a los mundos posibles o reales que contiene una obra literaria, permitiendo variedad de lecturas posibles; de la misma manera que no todo lector interpreta acertadamente las intenciones de los productos. Aún más, no todos los lectores enuncian de forma adecuada y aceptable sus hipótesis sobre el sentido logrado a partir de lo comprendido; pues esto depende, en suma, de sus competencias comunicativas lo cual, de suyo, genera riesgos, como el de la apertura múltiple de sentidos que puede tropezar con el "todo vale". En suma, la actualización semántico-pragmática de una obra está en manos del conocimiento subjetivo de un lector o, incluso, de la experticia lectora y de los saberes lingüísticos y del mundo de quien la enseña en ambientes letrados.

- Visto desde el otro lado del escenario comunicativo, es posible preguntarse por cuestiones como si los escritores proyectan su mirada y representan la realidad social de manera estricta, o si estos producen obras desde sus propios valores psíquicos y emocionales $\mathrm{y}$, desde estos, construyen una para-realidad que es la plasmada en sus productos simbólicos. En términos más simples, es el asunto de si una obra es ficción o realidad traspuesta. Para muchos investigadores, la obra literaria puede ser un modelo de comprensión situacional que provoca conocimientos pasados o evoca eventos de la historia, lo cual evidenciaría una relación entre la realidad-pivote y la imaginación literaria (Todorov, 2008). De seguir esto, aceptaríamos que la producción de texturas se da dentro de unas coordenadas sociohistóricas y políticas; por tanto, toda obra resulta ser la trasposición de esa realidad, solo que mediada por las capacidades retóricas y narrativas de su creador. De esta forma, la obra literaria establecería lazos comunicativos con acontecimientos, listos a ser comprendidos por las capacidades intertextuales y críticas de los potenciales lectores.

Pues bien, este tipo de perplejidades son comunes a propósito de la relación entre una obra, un lector, el autor y el contexto; están justificadas cuando se recuerda que el mundo referencial de una obra no siempre está anclada a un trabajo objetivo. Como también es viable afirmar que una obra, muchas veces, no activa el contexto cognitivo de un lector debido a la falta de coincidencias en los conocimientos con el autor, así como también al uso pragmático inadecuado de ciertas normas como el cruce de contextos, el desconocimiento de convenciones culturales o la ausencia de experiencias auténticas (Mendoza, 2004). Lo cual, a la postre, genera entropía; esto es, la pérdida de la información en la interacción establecida entre la obra y su lector, con su consecuente desviación en la captura del sentido (Bernárdez, 1995).

Así las cosas, la reflexión sobre la literatura comienza a encauzarse cuando se explicitan las diversas maneras como se comprende la relación entre el objeto, la obra literaria y el sujeto-lector dentro de un contexto sociocultural determinado. En este orden de ideas, sostenemos que en esta relación reposa la arquitectura central de una epistemología de la literatura como elemento clarificador de la correlación recién descrita.

Ahora, desde nuestro rastreo, esta compleja co-dependencia objeto-sujeto-texto-contexto se ha 
polarizado a lo largo de la historia en, al menos, cuatro tendencias epistemológicas, a saber: la racionalista, la empirista, la meta-lingüística y la vivencialista, siendo la primera y la cuarta, por lo menos en apariencia, fijaciones del objeto y del sujeto, respectivamente. A continuación, bosquejaremos algunos pormenores de cada una de ellas, con el fin de tomar una posición sobre cuáles directrices generales serían las más convenientes para una educación literaria en nuestro actual contexto social.

La primera postura, la racionalista, sacrifica el contexto de la obra literaria, convirtiéndola en una especie de matriz esencial autónoma, monádica y ecuménica. De esta manera, se concibe que obra literaria genera su propio sentido con independencia de lo que el sujeto pueda hacer con ella; de suerte que el lenguaje de una obra literaria no va más allá del significado que impronta los esquemas mentales de su autor.

Así las cosas, se admite que puedan existir varias significaciones epocales de una obra, incluso la justa (aunque de hallarla, nunca se sabría), pero su significado será fijo y eterno, es decir, capaz de resistir los cambios históricos, además de los múltiples lectores y sus lecturas. Uno de los pioneros de esta postura es el profesor Erick Hirsch (1967, 1976), quien planteó algunos procedimientos hermenéuticos aplicables a las obras literarias. Dentro de esos procedimientos propone la búsqueda, reconstrucción y resguardo de la carga intencional del autor, donde reposaría el significado marmóreo de la obra misma; por cierto, el pretil de su sentido original, objeto-de-estudio de la interpretación. Así que, para Hirsh, si se elimina al autor de la interpretación, se niega la regla que conduce a una interpretación válida.

La segunda postura abraza ese conjunto de discusiones sobre si la obra es la reproducción de un hecho (mímesis), si esta es la creación de un sujeto para transliterar un hecho (diégesis) o si hay compromiso de las dos en el momento de la producción. Este tipo de conceptualizaciones sobre la obra fueron reinterpretadas por el hermeneuta alemán Dilthey (1991) y, tras él, un buen legado de la hermenéutica occidental. Este autor propone entender la obra literaria como un producto cultural polivalente que no se explica, sino que se comprende, lo que involucra verla como dependiente de las circunstancias históricas que envuelven al autor. Ideas que se han reiterado en muchas empresas; así, por caso, para el filólogo y semiólogo Cesare Segre "el significado de la obra llega a ser más comprensible y elocuente si está introducido en su contexto" (1990, p. 21), pues lo importante es comprender a un autor de una obra mucho mejor de lo que este se pudo haber(se) comprendido. De esta suerte, a diferencia de la primera postura, los significados de una obra son producto del lenguaje, y si la función final de este es la comunicación; entonces, es indiscutible que el significado es un asunto eminentemente socio-cultural, gracias a ese doble dinamismo intrínseco entre sujeto, sociedad y significación.

En cuanto a la postura aquí llamada meta-lingüística, es sustentada desde variopintas posturas; verbigracia, el filósofo Ernst Cassirer (1990) supuso que toda actividad literaria se orienta hacia una digresión sobre la lengua, entendida esta como instrumento de comunicación, lo cual puede ser asumido desde dos aspectos. El primero, que permite apreciar el poder del lenguaje desde la expresión literaria (Foucault, 1996), y que se puede extender hasta la postura de Wittgenstein (1994), quien afirma que lo místico, aquello que evoca el misterio de la lengua literaria, es lo inexpresable, idea que jadeaba ya en las creencias de Mallarmé, Rimbaud o Joyce. Y, el otro aspecto resalta que aquello que se muestra en la obra literaria como creación auténtica está unida a la vida social, lo que permite encumbrar la idea de que toda obra tiene alto grado de isomorfismo con los hechos reales, como suele pasar, por caso, con la literatura histórica (Cfr. V. gr. White, 1992; Menton, 1993).

Finalmente, y con más actualidad, aparece la postura del vivencialismo, que comprende la obra como un recurso que nunca deja igual a su intérprete; esto es, que sirve de eje para la información, transformación o deformación del lector y para el acceso 
al conocimiento de sí a través de esa comunicación generada por la obra y el lector. Se trata, en suma, de un tipo de experiencia muy particular, puesto que enlaza lo erudito y lo pasional (Rosemblatt, 2002). Esto implica, por ejemplo, apoderarse de esa comunicación literaria desde metáforas como la del traductor, la del viajero o la del farmaceuta, mediante las cuales los sujetos reconstruyen su identidad personal y colectiva (Cfr. V. gr., Pennac, 1992; Petit, 2008; Larrosa, 2003). Si aceptamos que un lector se esfuerza por descubrir capas de sentido disfrazadas a través del tránsito por los entresijos textuales, tratando de convertir el lenguaje cifrado de la obra para poder encontrar en sus tramas significantes una medicina para sus propias incomprensiones, entonces la imagen del traductor, por caso, es muy solidaria con la de un lector literario.

A partir de lo anterior, aunque creemos que no hay un punto imparcial que nos informe cuál es la mejor postura para enseñar literatura, apostamos que la cuarta y la segunda postura, lejos de ser antagónicas entre sí, pueden tomarse solidariamente, puesto que dinamizan la tríada objeto/autor-sujeto-contexto al reconocer de forma inmediata sus extremos, permitiendo desgajar una comprensión sobre la complejidad conceptual de lo literario y dejando abierta, tanto la posibilidad de su cualidad politizada como socio-cognitiva; pero, además, porque este consorcio nos permite, por un lado, pensar la literatura como un objeto (de estudio) que muestra algo de algo, revela elementos de una manera tal que se muestra un acontecimiento testimonial, y también como una fuente histórica "inconsciente"; pero, por otro lado, flexibiliza la relación entre la literatura, la vida social y los sujetos que la moran y la recrean con sus actos. Así pues, esta concepción puede ser revisada a la luz de algunas metodologías que, sin ser definitivas, proponen acercamientos comprensivos sobre el sentido histórico de las obras, al tiempo que ilumina claves para pensar en su otra cara, las llamadas "escrituras de ficción" o "escrituras de invención" (Frugoni, 2006; Grafein, 1989; Hauy, 2011).

Ahora bien, expuesta la postura epistemológica asumida aquí desde un cierto eclecticismo que nos permite pensar la obra como un fruto histórico individual-colectivo, abrazamos la suposición que, en el tratamiento sistemático con las obras literarias dentro de espacios letrado, lo importante no es tanto el método, sino la fina y precisa definición del objeto, pues creemos que es necesario disponer primero de un objeto teóricamente constituido para poder trazar la ruta o método que conduzca a él (González, 1999). Dicho de otra forma, las determinaciones teóricas son importantes como instrumentos de orientación metodológica, puesto que ponen de relieve aspectos básicos destinados a gobernar cualquier investigación literaria (Saganogo, 2009). Al admitir esto, la cuestión se dirige hacia cuál es el objeto teórico de la literatura. Como sabemos, hay dispuesta una respuesta de antaño: La literariedad, lo que hace que un producto literario sea tal y no otro tipo de textura.

Aunque ha habido varias teorías sobre el entendimiento de La literariedad, tal como lo compila brillantemente el crítico cultural británico Terry Eagleton (1983), ${ }^{2}$ lo cierto es que se mueven entre definiciones esencialistas y convencionalistas. Nuestra propuesta se inclina a definir La literatura desde una postura esencialista débil, explicada también por Eagleton (2013), y que nosotros acogemos y modulamos con una función sociopolítica del arte (Grass y Goytisolo, 2002). Así, pues, pensamos que la literariedad de la obra literaria se manifiesta cuando satisface algunas propiedades intrínsecas que le corresponden de suyo, siendo uno de esos aspectos la de ser "(...) una maquinaria semiótica que permite reconocer avatares históricos de los colectivos y mantener un pasado presente para poder proyectarse en el futuro" (García-Dussán, 2018b, p. 77). Lo cual está unido a esa noción que propone Analía Gerbaudo (2008) de leer la literatura "[...] en su ángulo subversivo, en su costado político, en su carácter de aparente sobra, o detritus que, no obstante, vuelve sobre el resto de los discursos de la cultura para desmontarlos" (p. 58).

2 Así, por ejemplo, que la obra literaria es ficción, o una deformación de la lengua, 0 un discurso no pragmático, 0 un acto de habla que pone en evidencia la identific ación entre literariedad y performatividad, etc. (Eagleton, 1983). Pero, también podemos sumar que es un discurso metalingüístico, matesis como opuesto a la mímesis, semiosis, máquina de memoria, práctica socio-cultural, forma de exploración (peripatos), discurso pedagógico, discurso, identitario, etc. 
Aún más, esta postura adoptada, al no ser totalitaria, es flexible con una mirada funcionalista frente a la obra literaria; lo que permite, además, hacer una metateoría de la obra literaria sin descuidar sus vasos comunicantes con el pasado histórico remoto o reciente y, finalmente, desgarrando así la mónada posible de un esencialismo absoluto con todos los avatares que presenta lo social. En este orden de ideas, al concebir La literatura como un objeto-de-estudio que debe satisfacer, por lo menos, unas de las fundadas propiedades íntimas a su naturaleza simbólica, ${ }^{3}$ podemos ahora bosquejar en una metodología particular para la enseñanza de la Literatura (La literariedad) en nuestro país.

Pues bien, de la pluralidad de diseños posibles que se han ofertado en el último siglo para abordar sistemáticamente la literatura (Cfr. V. gr. Eagleton, 1983; Lázaro Carreter, 1980; López Eire, 2002; García Berrío, 1994), apostamos por un camino inspirado en los trazos y esquemas que ofrece el paradigma científico de la semiótica literaria (especialmente, la sucedida después de los años setenta del siglo pasado), y complementada aquí con algunos abecedarios de la propuesta investigativa del análisis discursivo (que incluye los estudios retóricos y neorretóricos) y que, incluso, está armónicamente insertada, como junción, en los actuales Estudios culturales.

Para García Berrío (1994), la semiótica literaria plantea que una vía para afrontar la rigurosidad analítica de las obras implica concebirlas como estructuras sígnicas de alta complejidad. Y, para lograr tal meta, el examen sugerido inicia su recorrido desde el polo más visible o sintagmático, encumbrado sus esfuerzos hacia el contexto de la obra, que ya tocarían las fibras más tácitas de la obra, sin descuidar aspectos sociohistóricos del autor. Según Bobes Naves (1989) esta disciplina, por lo menos la precursora, asegura el análisis objetivo al concentrarse en la estructura, pero sacrifica con su apuesta el fundamento "espiritual" del material sígnico, razón por la cual hay que buscar

3 En nuestra propuesta, enlistamos algunas de esas cualidades ontológicas de la obra literaria, tal como la trans-acción de mundos, experiencias de identificación y alteridad, procesos de trans-posición y trans-figuración, ambigüedad referencial e instrumento de crítica social (Cfr García-Dussán, 2018a). otros modelos que permitan abrir la obra al seno de la vida social en la que esta se instala.

Consideramos que este ensanchamiento lo podemos apoyar con algunas premisas del análisis discursivo, que no solo atiende a la forma, sino también al contenido o función de los productos simbólicos (Renquema, 1999), con lo cual nos permitimos reconocer que la literatura es un producto discursivo; es decir, un producto "sujeto a los vaivenes de contextos psicológicos, situacionales, sociohistóricos, de producción y de recepción" (Barrera, 2007, p. 147). Con esta acción complementaria, avanzamos el tránsito de una semiótica estrecha a una semiótica cultural (Jiménez, 2015); asegurando sobre la materialidad de la obra el estudio de una "doble codificación", típica de lo que Bajtín (1979) llamó "géneros secundarios", a saber: la estructura o significado inmanente y el de las capas de sentido trascendente que poseen los textos culturales, lo que permite suponer una intención de uso y una interpretación de mensajes.

De esta forma, dicho sea de paso, creemos resolver, en gran medida, dos cuestiones arriba insinuadas. La primera, centrada en las disyunciones epistemológicas arriba descritas en las posturas históricamente determinadas y que van de la obra-mónada a la obra-subjetivista, pasando por el reconocimiento de que toda obra circula dentro de una comunidad regido por una diversidad de contextos situacionales, históricos, culturales, etc.

La otra cuestión es que, con esta acción, aseguramos que la obra literaria se nos convierta en "una puesta en escena de lo simbólico, no del contenido, sino de sus desvíos", razón por la cual su análisis debe darse a la luz de una "teoría liberadora del significante" (Barthes, 1994, p. 247). Esto es, no solo reconocemos la obra como discurso en su contexto, sino todo el conjunto de variables cognitivas y prácticas que deben activarse para crear o actualizar la obra; elementos que, sin duda, son el fundamento de una manipulación, bien sea en el orden de la comprensión (bien valorada) o de la producción/ creación (intencionalmente buscada) y que hacen de una obra literaria una "obra abierta". Es decir, algo que ponemos entre ojos o tomamos entre manos y que nos resulta inconclusa, ambigua y dúctil 
(Eco, 1992), razón por la cual, nos insta a tener en cuenta "diferentes tipos de contextos, conocimiento previo, conciencia comunicacional, valores, principios, creencias y, por su puesto, formas lingüísticas concretas que se ponen en práctica para englobar todos estos factores" (Barrera, 2007, p. 147).

Ahora, a partir de esta apuesta metodológica, podemos avanzar la construcción de una epistemología de la literatura y cristalizar unos principios de acción, a propósito de la tarea de comprender o de producir una obra literaria como discurso. Así, pues, se completa el panorama de la epistemología literaria aquí trazada $y$, de paso, nos permite escudriñar los modos como un escritor o un lector organiza la realidad histórica.

El primero de estos principios operativos afirma que toda obra, con lo que dice, quiere decir algo más; y ese decir con ese plus de sentido está inscrito en unas coordenadas contextuales (físicas, sociohistóricas, culturales y cognitivas), puesto que nadie dice nada desde la nada (Segre, 1990). Pero, y aquí se instala el tercer principio el cual alerta que, pese a que toda obra está inscrita en contextos socioculturales y políticos, esta no se limita a tales determinaciones, ya que todo texto es una máquina perezosa (Eco, 1987), además de abierta, dinámica, compleja y atemporal que captura al propio lector. Finalmente, ese contexto cognitivo que está implícito en el tercer principio admite que el lector sea coautor de la reconfiguración de la obra como discurso, el leedor que llena vacíos, completa o actualiza los contenidos de la forma con sus propios "horizontes de sentido" gracias a su pensamiento inferencial; pero, sobre todo, al stock de saberes logrados desde las experiencias de su mundo-dela-vida y marcados por combinaciones de tipo sociolingüístico (García-Dussán, 2008; 2015), certificando así la alerta de van Dijk (2003) de justificar la integración de ideologías, identidades sociales y los saberes. Activados estos principios, la manipulación de la obra (en su comprensión o su producción) deberá regirse por el recorrido a través de niveles de análisis (Constitución de lo textual, Combinación o representacional y Uso social o interpersonal), los cuales pueden ser abordados en dos grandes fases, a saber: la analítica y la interpretativa.
Finalmente, al respecto de nuestra propuesta metódica, afirmamos que la resolución de las dos macro fases, se ajustan a aquello que llamamos la "ecuación de oro" en la manipulación de la obra y que se puede presentar así: Análisis + Interpretación = Comprensión. El momento de la tensión analítica o del análisis, propiamente dicho, reduce la incertidumbre de sentido a través de un trabajo sistemático de distinción, separación y examen por niveles (labor intratextual); mientras que la distensión interpretativa se da como un diálogo abierto con el contexto y con otros textos. Al tiempo que se apoya en el tratamiento pausado y habilidoso de simbolismos, imaginarios, saberes, ideologías y valores, tales como las opiniones, los estereotipos y los prejuicios adheridos en los hilos de la obra. Pero, antes de proponer un modelo epistemológico basado en las claridades logradas, reconstruiremos un mapa de cómo se ha venido enseñando la literatura en nuestro medio.

\section{Devenir de la enseñanza de la literatura en el contexto educativo colombiano actual}

La mayoría de las investigaciones y reflexiones generadas a propósito de la enseñanza de la literatura en nuestra nación, especialmente en los tres últimos lustros, permiten ver cómo se ha instalado la literatura en el contexto educativo, esencialmente anudada con propuestas pedagógicas y didácticas confusas y mixtas, sumada a la acumulación de información formalista y estructuralista, pesquisas basadas en el método periodizante o geográfico que exige la acumulación y memorización de datos; además del privilegio de la didáctica de la oralidad y la lecto-escritura (resquicio de vieja data) que se preocupa más por la comprensión de las estructuras morfo-sintácticas y ortológicas de la lengua materna que por la agudeza analítica contextual y crítica. Todo lo cual se sobrepone a la lectura de las obras literarias como comprensión y la composición como invención subversiva y metalingüística (Cruz, 2005).

Como se entiende, estas tendencias opacan la autonomía el lugar de una posible pedagogía de la literatura, tal como lo vienen revelando desde comienzos de siglo los profesores Fabio Jurado (2004), Alfonso 
Cárdenas (2004), Fernando Vásquez (2006), Beatriz Robledo (2011) o Guillermo Bustamante (2015), con lo cual se malgasta el esfuerzo de mostrar la necesidad de la literatura en la educación estética. Es decir, en aquel esfuerzo por sacar a la luz lo oculto al sentir y pensar la realidad o, más simplemente, de hacer visible lo invisible de las texturas que dan cuenta de lo que nos es nuestro (Eisner, 1995), nuestro pasado y nuestra actualidad social como acto fundamental de una co-construcción de la subjetividad y de la identidad social.

Más recientemente, Martínez y Murillo (2013) diagnostican el estado actual de la enseñanza de la literatura y demuestran el uso reiterativo de las teorías literarias, pero con predisposición hacia el inmanentismo y al reduccionismo, lo que demora el trabajo sobre las capas profundas de las texturas; esto es, el salto del código al mensaje. En términos ricoeurianos, la suma de un momento de explicación, seguido de un momento de interpretación.

No obstante, hay experiencias pedagógico-didácticas que constatan que muchos docentes del área se han visto sacudiendo de estos empachos. En efecto, los nuevos esfuerzos pedagógicos para la enseñanza literaria han venido favoreciendo, por un lado, elementos de la Semiótica, que reconoce la relación autor-texto-contexto y, por otro, de la Estética de la recepción, que suma la importancia del trabajo activo del lector (lector-texto-contexto-autor). Situación que permite que la literatura en la escuela sea una práctica social compleja que deviene en una experiencia que enriquece las dimensiones cognitiva (comprensión y producción argumentativa), estética (alianza logopática, donde coincidan el mundo de la lectura y la vida del lector), histórica (lecturas contextuales) y semiótica (Lectura sobre juegos de lenguaje cualificados por simbolismos y cruces de campos semánticos/pragmáticos), tal como ya se había propuesto en los Lineamientos (2008).

Así las cosas, la literatura en la escuela colombiana ha sido pensada, propuesta y actuada en escenarios democráticos que exigen acciones dialógicas (aquello que Bajtín (1981) llamó la "imaginación dialógica) $y$, por tanto, asumiendo en primer plano el disenso, la indagación creativa, la experimenta- ción y el reconocimiento de experiencias y de reconocimiento de otras voces y sus variopintas formas de insertarse (intertextualidad). Todo lo cual exige de los participantes el que sean lectores y escritores expertos en el trabajo abductivo y relacional que, de la mano del asombro, la sospecha y el afinamiento de la creación de hipótesis de sentido sobre las implicaturas discursivas encubiertas en los textos literarios, comiencen a alejar aquel tratamiento escolar donde las obras se ven no como un proceso de pensamiento crítico, sino como un producto de laboratorio, que reduce el texto literario a un objeto que se disecciona para percibir sus entresijos más obvios, dejando al profesor de literatura en el lugar de un enemigo de la literatura misma (Cfr. Ferrer, 2004; Moreno y Carvajal, 2010; Baquero, 2015). Un trabajo, por cierto, que ya no trate de periodos o épocas, sino de temas en consonancia con otras manifestaciones artísticas (Vásquez, 2012).

Pero también comienzan a consultarse investigaciones que promueven el uso de la literatura en los currículos asociados a las coyunturas más urgentes del país a propósito de su época de esperanzas por otro tipo de nación; una más incluyente y más solidaria donde no haya más repetición de las violencias visibles e invisibles. Así por caso, aquellas que asocian productos literarios como vehículos para indagar la identidad social (García-Dussán, 2018b); o investigaciones que inician los estudios de la literatura y la memoria histórica "anclado a las posibilidades pedagógicas de la lectura que escenifican el conflicto colombiano y permiten acercarse a los acontecimientos históricos, desde el campo de la sensibilidad y la percepción estética que proporcionan el arte y la imaginación literaria" (García y González, 2019, p. 150). Cuyo antecedente se encuentra en la publicación intitulada $\mathrm{La}$ literatura como arte-facto de la memoria histórica en la escuela (Castillo, García y González, 2017), producto de trabajo en la Organización Coalición contra la vinculación de niños, niñas y jóvenes al conflicto armado en Colombia (Coalico), quienes encontraron las bases legítimas en reflexiones como las avanzadas recientemente por el profesor de literatura Víctor Viviescas (2016). 
Asimismo, se encuentran nuevos e interesantes maridajes como el uso de la literatura y su relación con la sensibilidad moral, agenciada por investigadoras como Caterine Pardo (2019), donde las obras literarias se instalan como vehículos para la comprensión de la realidad social y el reconocimiento del otro y de lo otro, en beneficio de una cultura de paz. En ella, la literatura se concibe como "un ejercicio que pasa por la existencia de aquel que escribe y toma el lenguaje para crear mundos o realidades paralelas a su mundo, su historicidad, su contexto y lugar; y aquel que lee, el cual interpreta los mundos que se le presentan para apropiarse de ellos y realizar sus propias interpretaciones" (Pardo, 2019, p. 50).

Otra tendencia cada vez más estudiada es la sociedad literatura y nuevas tecnologías info-comunicacionales (NTIC), ora en el ámbito de su difusión (piénsese en las bibliotecas virtuales), lo que ha generado el acontecimiento de la literacidad electrónica o nuevas prácticas letradas de comprender y producir (Cassany, 2012); ora en el ámbito de la coproducción (como las obras escritas colectivamente usando la Web 2.0), a tal punto que se estudia con holgura la literatura digital y su convivencia con la literatura tradicional. Un ejemplo de esto es la plataforma de Narratopedia, creada por el profesor Jaime Alejandro Rodríguez (2011) en la Pontificia Universidad Javeriana, en la que se evidencia la experiencia de una escritura colectiva en red, donde participan nuevos lectores con nuevas posibilidades de interpretación sobre el texto literario, resalta que las NTIC ofrecen la posibilidad de mediar con la realidad y transformarla. Es que, desde su nacimiento, en el primer semestre de 2008, en este sitio web los usuarios vienen aportando textos, videos, audios y animaciones para contar historias sobre diferentes ejes temáticos (V. gr. la universidad, el cuerpo, las mudanzas y las crónicas de viajes). A partir de esto, se crea una malla de contenidos que pueden ser valorados y comentados por los visitantes, $y$ que actúa de la misma manera como se hace en un $b l o g$, admitiendo archivos que se pueden arrastrar desde Youtube o Flickr.

\section{Algunas directrices para una educación literaria en el devenir de nuestra Escuela}

A partir de este bosquejo epistemológico y del reconocimiento de los avances y posturas que se han fijado en nuestro medio a propósito de la enseñanza de la literatura, podemos arriesgar ahora una reflexión englobante que permita (re) inscribir la literatura en el marco de las condiciones socio-culturales de nuestra escuela, que son las condiciones de la nación misma. Para lograr esto último, proponemos que la literariedad de los corpus literarios sea tratada e investigada como un elemento interdisciplinar e interdiscursivo que hace parte de la educación, en general, y de la educación en ciencias humanas, en particular; especialmente, como recurso de memoria colectiva y de vitalidad de una lengua-nación.

Estamos de acuerdo con Amador y Muñoz que la educación es un "proceso y producto de la sociedad [que] pretende reproducir determinados valores y prácticas, aunque eventualmente puede constituirse en proceso de formación, transformación y liberación" (2018, p. 48). A partir de esto último, reconocemos que la literatura puede ayudar a cumplir esa meta de (trans)formación, evidente en las recientes posturas epistemológicas en literatura (V. gr. la vivencialista) en la medida en que, situada la obra en un contexto, asociada a la cultura, y cualificada como un discurso de denuncia, cambia la cosmovisión y la actuación del lector, bien sea comprendiendo sus líneas ilocutivas, o bien generando texturas que inserten elementos que ayuden a promover la generación de lectores críticos e independientes sostenido en el poder del conocimiento, y que se manifiesta cuando el lector "construye una posición frente a los textos, la ubicación como un heredero siempre fiel-infiel, es decir, que sigue y se aparta, que toma pero transforma, que inventa algo nuevo con sus actos de lectura" (Gerbaudo, 2008, p. 62).

Esto está en armonía con la idea que la educación literaria en nuestros espacios escolares se practique como un fenómeno de sentido que envuelva el desarrollo de habilidades de pensamiento tales como 
el análisis, la síntesis, la inferencia, la interpretación y la argumentación (Cárdenas, 2000; 2006). Así, se convierte en un pre-texto con dos caras visibles: la del sujeto-lector o sujeto-creador, cuyas acciones terminen en una reingeniería de cosmovisiones frente al panorama socio-cultural y, por tanto, instala maneras subversivas y no normatizadas de leer el mundo social con apoyo en las obras literarias; todo lo cual requiere la intervención pedagógica, bien sea desde el rol de investigador, animador, profesor o docente-investigador. Todo esto para contribuir con el recurso de una formación de sujetos críticos.

De esa manera, estamos ante la posibilidad de concebir la educación literaria en espacios universitarios que oscilan en un doble objetivo. A saber: ora, el de acompañar la generación de investigaciones centradas en la educación literaria, como recurso para la comprensión del nosotros colectivo y del devenir cultural; ora, el de transformar capas sociales que se empoderen de su mundo social para re-leerlo o re-crearlo de una manera crítica e innovadora, usando su racionalidad estética, sujetos capaces de leer o fundar realidades desde la armonía entre el pensamiento y la sensibilidad.

Frente a esta gran meta, podemos endosar otras tareas a la educación o formación literaria. Por ejemplo: el fortalecimiento, tanto de las reflexiones teóricas como pedagógicas, además de los recursos didácticos para el abordaje de obras literarias en los contextos escolares de diversos niveles de educación; la co-construcción de las bases teóricas para el entendimiento de la literariedad en épocas actuales y de los elementos de una pedagogía de la Literatura situada; el diálogo con las tradiciones científicas que contribuyan al desarrollo de la Didáctica de la Literatura; las diversas formas en las que se edifica la personalidad del sujeto-lector/creador y de cómo se enriquecen sus experiencias comunicativas y su visión de mundo e, incluso, la reflexión sobre las propias prácticas del investigador acerca de los modos de apropiación del conocimiento del mundo a través de experiencias estéticas, y de la experiencia lectora/escritora de lo literario (García-Dussán, 2016).

Ahora, a partir de todo esto, creemos que los procesos propios de la educación literaria que aquí describimos. Para la comprensión y para la creación son las bases de una pedagogía de la literatura situada/ sincrónica; entendemos que para fortalecer las habilidades escriturarias no hay que, a secas, escribir, sino previamente asegurarse de destrezas comprensivas. Por lo tanto, el asunto de la lectura comprensiva se nos ofrece como un punto arquimediano para caminar rutas pedagógico-didácticas e investigativas, el punto para mover la educación literaria. De esta suerte, tenemos que un refuerzo y apoyo en la comprensión de textos literarios, nos permitiría certificar progresos en la producción de textos de ficción o creación, cuya labor la ubicamos en las formas didácticas de des-automatizar la lengua-sistema y de fortalecer habilidades metalíngüísticas.

El resultado de todo esto es, tanto para el educando como para el investigador mismo, el fortalecimiento de la competencia literaria, el conjunto de saberes, habilidades y estrategias de autorregulación que permiten a los sujetos acceder a las obras literarias para comprenderlas o (re)crearlas (Colomer, 1998; Lomas 2006). El reto de fortalecer tal competencia tendría, al menos, cuatro aristas prácticas ancladas en los procesos de la modalidad escrita de la lengua, a saber: las lecturas orientadas para despertar simpatía y fruición; la vigorización del trabajo abductivo sobre los entresijos de las obras; el tratamiento crítico-intertextual e interdiscursivo a propósito de las obras $y$; finalmente, el desarrollo de la creatividad con base en el conocimiento estructural y funcional de la lengua. Y, para dinamizar estas prácticas de muestra propuesta en el contexto educativo universitario, hacemos notar que una educación literaria puede diseñarse atendiendo, al menos, a estas tres alternativas pedagógicas:

a. Las nuevas sensibilidades, que trazan un "nuevo mapa cultural" gobernado por lo analógico y lo visual (Martín Barbero, 1998; 2003). Razón por la cual debe regirse por la convivencia intertextual que ponga en un mismo plano las obras literarias con otros códigos como el cine, la televisión, el uso de la web 2.0, la música, el teatro, el arte des-regulado (performances, happenings, instalaciones, etc.), bajo el manto de una Pedagogy of multiliteracies, tal como 
lo propuso en 1996 The New London Group. Aquello que más recientemente Huergo llama “alfabetización posmoderna” (2017, p. 51), y que también insinúa Gerbaudo $(2008 ; 2013)$ como parte de las "buenas prácticas de enseñanza de la literatura”. Para nosotros, esto aseguraría la fruición en el contacto con las obras, bien sea desde el rostro de su comprensión, o desde el de su producción.

b. La explicación de que toda obra literaria es un producto creativo, poiético y abierto, unido a la la toma de conciencia que la lengua es arbitraria, figurativa e indexical. Esto obliga al lector de obras literarias a usar suficientemente su pensamiento inferencial para acceder, como cierre del proceso, a la confirmación de una ausencia de univocidad de los significantes que, al explotarse en la obra como material crítico, admite el pensamiento crítico porque desmitifica y re-escribe, como un palimpsesto, la historia tergiversada u olvidada de una nación desde sucesos concretos pero anudados a una red histórica mayor cruzada por la multiplicación de las violencias - política, insurgente y del problema narco-. Como lo dejan ver con ciertos escrúpulos estéticos las novelas de García Márquez; pero, también, las de Evelio Rosero, Martha Orrantia, Juan Gabriel Vásquez, Juan Álvarez, Pablo García, William Ospina, Silvia Galvis y un enorme etcétera. ${ }^{4}$

c. La revisión y profundización de las concepciones y teorías de aprendizaje que se expresan en las prácticas de la enseñanza literaria,

4 Si tomamos la obra de la profesora Martha Lucía Orrantia, Mañana no te presentes (2016), encontramos que trata sobre la toma del Palacio de Justicia en noviembre de 1985, para muchos una historia llena de preguntas, espejismos, pero, sobre todo, una historia llena de secretos, envueltos en la memoria oficial. Orrantia, basada en los hechos históricos, se acerca de nuevo a la catástrofe de la toma y retoma del Palacio desde la voz de una militante testigo y parte de la historia oficial (de la Quinta Columna del M- 19 y parte de los 35 guerrilleros que ingresaron al Palacio) llamada Yolanda, para abrir la herida y dejar una nueva versión de los hechos, tapando vacíos y zonas oscuras de la historia. "Mañana no te presentes" fue una alerta tardía del amante de Yolanda. La retoma del palacio fue una trampa: el Ejercito sabía del plan guerrillero; entonces, los esperó, lo encerró y los masacró; como a ratas atrapadas. Sobrevivió una guerrillera, que, exiliada luego en México, murió sola. puesto que determinan la configuración de formas particulares de intervención áulica, además de maneras de abordar los contenidos en relación con la lengua, las formas de saber-ignorar, las formas de orientar la creatividad escrituraria y los supuestos teóricos que maneja el maestro respecto a cómo enseña y cómo aprenden sus estudiantes (Litwin, 1997). En suma, la revisión dentro y desde el aula sobre las condiciones de una buena práctica de enseñanza de la literatura.

Así pues, si unimos las tres alternativas como complemento a las ya revisadas por los expertos en el campo en Colombia, y arriba abreviados, encontramos un ambiente áulico refrescado y más acentuado a las necesidades formativas de nuestra escuela actual, si queremos pensar que la escuela sirve a la sociedad y no al revés, y que armoniza muy bien con esa escasez de inventivas para reconstruir nuestro pasado, como premisa para una cultura de paz tras más de medio siglo de historia de horror, y que requiere de estrategias para analizar la representación que, de los eventos y de los sujetos, se hace desde las diferentes enunciaciones (Farné y López, 2016).

\section{A manera de cierre}

Llegados en este punto, verificamos que el ejercicio de equipar con detalles una epistemología de la literatura y aprovechar el esfuerzo para obtener de allí unos parámetros para asociar la literatura con los espacios formativos, sin descuidar lo sucedido en el campo en los últimos años en Colombia, da como resultado un croquis sobre cómo entender la literatura y cómo operar con ella en los espacios áulicos de formación universitaria. Apostamos, entonces, por una epistemología que deja una propuesta tanto conceptual como metodológica, la que dan paso a la exposición de unos principios pedagógicos situados, a propósito de nuestra situación social y política frente al pasado reciente.

De todo esto se desgaja algo que consideramos cardinal en nuestra propuesta: la meta final de las labores en una educación literaria no puede 
prescindir de esta doble premisa. A saber: por un lado, que los discursos literarios deben ser un pretexto para la emancipación y la transformación de los sujetos y para la co-construcción de la otra-memoria en pro de la verdad y la reconciliación con lo despintado o embrollado; por otro lado, que el desarrollo investigativo en este campo, y tal como ya lo había anunciado Halliday (1989), esté pensado en un esquema que, desde el matiz interdisciplinar, asegure el diálogo entre la historia, la semiótica aplicada, el análisis del discurso, las investigaciones cognitivas sobre el lenguaje y otras lógicas disciplinares. Solo así, creemos, las prácticas escolares con obras literarias adquirirán un nuevo aire, reiterando una función concreta frente a esa pulsión colectiva de olvido y a esa acción de esconder la basura debajo del tapete, en lugar de enfrentarla y deshacerse de ella por vías más sensatas.

\section{Agradecimientos}

Gratitudes al Centro de Investigación y Desarrollo Científico (CIUD), de la Universidad Distrital, Francisco José de Caldas, ya que gracias a su apoyo fue posible la producción de este artículo de reflexión, derivado de la investigación institucionalizada con el código 2419167418.

\section{Referencias}

Amador, J. C. y Muñoz, G. (2018). ComunicaciónEducación en Abya Yala: lo popular en la reconfiguración del campo. Revista Nómadas, (49), 47-67. https://dx.doi.org/10.30578/nomadas.n49a3

Bajtín, M. (1979). Estética de la creación verbal. Siglo XxI.

Bajtín, M. (1981). The Dialogic Imagination: Four Essays. University of Texas Press.

Baquero, P. (2015). Didáctica de la literatura: interdisciplina y sospecha. C. Guevara (ed.). Enseñanza de la literatura: perspectivas contemporáneas (pp. 29-47). UD editorial.

Barthes, R. (1994). De la obra al texto. En El susurro del lenguaje. Más allá de la palabra y la escritura (pp. 73-82). Paidós.

Bernárdez, E. (1995). Teoría y epistemología del texto. Cátedra.

Bobes, M. C (2008). Crítica del conocimiento literario. Arco/Libros.
Bobes, M. C. (1989). La semiología. Síntesis.

Bobes, M. C. (2012). Realidad, Literatura y Conocimiento en la novela de Cervantes. Arco/Libros.

Bustamante, G. (2015). Algunas vicisitudes de la enseñanza de la literatura. En C. Guevara (ed.). Enseñanza de la literatura:perspectivas contemporáneas (pp. 141-158). UD editorial.

Cárdenas, A. (2000). Elementos para una pedagogía de la literatura. Cuadernos de Literatura, 6(11), 1-18.

Cárdenas, A. (2004). Elementos para una pedagogía de la literatura. Universidad Pedagógica Nacional.

Cárdenas, A. (2006). Sentido y discurso: Para leer mejor. En L. Ramírez Peña y G. Acosta. (Comps.) Estudios del discurso en Colombia (pp. 295-311). Sello editorial de la Universidad de Medellín.

Cassany, D. (2012). En_línea. Leer y escribir en la red. Anagrama.

Cassirer, E. (1990). Filosofía de las formas simbólicas. Fondo de Cultura Económica.

Castillo, M. C., García, N. y González, F. (2017). La literatura como arte-facto de la memoria histórica en la escuela. Coalición contra la vinculación de niños, niñas y jóvenes al conflicto armado en Colombia (Coalico).

Colomer, T. (1998). La formación del lector literario. Síntesis.

Cruz, M. (2005). Didácticas de la literatura como proceso de significación y desarrollo de la competencia discursiva. Revista Poligramas, (24), 96-112.

Eagleton, T. (1983). Una introducción a la teoría literaria. Fondo de Cultura Económica.

Eagleton, T. (2013). El acontecimiento de la literatura. Península.

Eco, U. (1992). Obra abierta. Planeta-Agostini

Eisner, E. (1995). Educar la visión artística. Paidós.

Farné, A. y López, F. (2016). Comunicación para la Paz: una propuesta pedagógica para el Cambio Social. Opción, 32(9), 644 - 662.

Fenstermacher, G. (1986). Tres aspectos de la filosofía de la investigación sobre la enseñanza. En M. Wittrock (ed.) La investigación de la enseñanza, I. Enfoques, teorías y métodos (pp. 148-159). Paidós.

Ferrer, Y. (2004). La literatura en contexto educativo. Revista Grafía, (2), 119-129.

Foucault, M. (1996) De lenguaje y literatura. Paidós.

Frugoni, S. (2006). Imaginación y escritura. La enseñanza de la escritura en la escuela. Libros del Zorzal. 
García Berrío, A. (1994). Teoría de la literatura. La construcción del significado poético. Cátedra.

García-Dussán, É. (2008). Manual de hifología. Análisis e interpretación de textos. Unisalle.

García-Dussán, É. (2015). Investigación en lengua materna. Camino y fundamentos. UD editorial.

García-Dussán, É. (2016). La cotidianidad de la literatura; la literatura en la cotidianidad. En S. Moreno, y A. Suárez (Eds.) Encuentro de saberes: un pretexto para pensar las pedagogías de la oralidad, la lectura, la escritura y la literatura en el siglo XXI (pp. 73-90). uD editorial.

García-Dussán, É. (2018a). Y la literatura, ¿cómo va en la enseñanza de la lengua materna? Revista Enunciación. 23(1), 74-86. https://doi.org/10.14483/22486798.12557

García-Dussán, É. (2018b). El secreto de la laberíntica soledad. Huellas de la identidad social en la obra del joven García-Márquez. ud editorial.

García, N. y González, F. (2019). Literatura y memoria histórica en la escuela. Una experiencia pedagógica e investigativa. Folios, (49), 149-160. https://doi. org/10.17227/folios.49-9402

Gerbaudo, A. I. (2008). La literatura en la escuela secundaria argentina de la postdictadura. Horizontes Educacionales, 13(1), 55-66.

Gerbaudo, A. I. (2013). Algunas categorías y preguntas para el aula de literatura. Revista Álabe 7, 1-16.

González, C. (1999). Función de la teoría en los estudios literarios. Limusa.

Grafein. (1981). Teoría y práctica de un taller de escritura. Altalena.

Grass, G. y Goytisolo, J. (2002). Mundialización, miseria social, racismo, nacionalismos. Le Monde Diplomatique/el Dipló/Abril, 54-58.

Halliday, M.A.K. (1989). El lenguaje como semiótica social. México: Fondo de Cultura Económica.

Hauy, M. E. (2011). La escritura de ficción en el aula como problemática. Aportes Científicos desde Humanidades, 9(9), 2-17.

Hirsch, E. D. (1967). Validity in interpretation. Yale University Press.

Hirsch, E. D. (1976). The aims of interpretation. Chicago University Press.

Huergo, J. (2017). Las alfabetizaciones posmodernas, las pugnas culturales y los nuevos significados de la ciudadanía. Revista Nómadas, (50), 49-60.
Jiménez, M. (2015). En torno al desarrollo de la semiótica literaria y el concepto de cultura. Revista Dialogía, 9, 208-229.

Jurado, F. (2004). Palimpsestos, la literatura en el contexto escolar. Revista Literatura: teoría, historia, crítica, (6), 269-296.

Larrosa, J. (2003). La experiencia de la lectura. Estudios sobre literatura y formación. Fondo de Cultura Económica.

Lázaro, F. (1980). Estudios de lingüística. Crítica.

Litwin, E. (1997). Las configuraciones didácticas. Paidós.

Lomas, C. (1999). Cómo enseñar a hacer cosas con las palabras. Teoría y práctica de la educación lingüística. Volumen 2. Paidós.

Lomas, C. (2006). La educación literaria en la enseñanza obligatoria. En Lomas, C. (ed.) Enseñar lenguaje para aprender a comunicarse (pp. 23-50). Magisterio.

López, A. (2002). Retórica clásica y teoría literaria moderna. Arco Libros.

Martín-Barbero, J. (1998). Un nuevo mapa cultural. En Y. Campos e I. Ortiz. (comps.). La ciudad observada: violencia, cultura y política (pp. 4-12). Tercer Mundo.

Martín-Barbero, J. (2003). Figuras del desencanto. Revista Número, 36, 66-71.

Martínez, Z. y Murillo, Á. (2013). Concepciones de didáctica de la literatura en Colombia durante los últimos diez años. Revista Grafía, 10(1), 175-194.

Mendoza, A. (2004). La educación literaria. Bases para la formación de la competencia lecto-literaria. Aljibe.

Menton, S. (1993). La nueva novela histórica de la América Latina, 1979 - 1992. Fondo de Cultura Económica.

Ministerio de Educación Nacional. (2008). Lineamientos curriculares de lengua castellana. Magisterio.

Moreno, M. y Carvajal, E. (2010). La Didáctica de la Literatura en Colombia: Un caleidoscopio en construcción. Revista Pedagogía y Saberes, (33), 99 - 110. https://doi.org/10.17227/01212494.33pys99.109

Orrantia, M. L. (2016). Mañana no te presentes. Random House.

Pardo, C. (2019). Literatura y sensibilidad moral: el lugar de la educación universitaria en el actual contexto colombiano. Ciudad Paz-ando, 12(1), 47-55. https:// doi.org/10.14483/2422278X.13647

Pennac, D. (1992). Como una novela. Anagrama.

Petit, M. (2008). Una infancia en el país de los libros. Océano Travesía. 
Renquema, J. (1999). Introducción a los Estudios sobre el Discurso. Gedisa.

Robledo, B. (2011). La literatura como espacio de comunicación y convivencia. Lugar editorial.

Rodríguez, J. A. (Comp.) (2011) Narratopedia: reflexiones sobre narrativa digital, creación colectiva y cibercultura. Javegraf.

Saganogo, B. (2009). El concepto de literariedad: estatuto y postulado del texto literario. Revista Letralia, 13(206), 12-45.

Segre, C. (1990). Semiótica filológica. (Texto y modelos culturales). Universidad de Murcia.

Todorov, T. (2008). Los abusos de la memoria. Paidós.
Van Dijk, T. (2003). Racismo y discurso de las élites. Gedisa.

Vásquez, F. (2006). La enseña literaria. Kimpres.

Vásquez, F. (2012). Navegar en el río con saber de marinero: aportes para una didáctica de la literatura. Revista Actualidades Pedagógicas, (59), 85-98.

Viviescas, V. (2016). El arte en los tiempos del conflicto: el reclamo de la víctima. Calle 14, 11(20), 14-33. https:// doi.org/10.14483/udistrital.jour.c14.2016.3.a02

White, H. (1992). Metahistoria. La imaginación histórica en la Europa del siglo XIX. Fondo de Cultura Económica.

Wittgenstein, L. (1994). Tratactus Lógico Philosophicus. Altaya. 
